\title{
A model for estimation of the demand for on-street parking
}

\author{
Madsen, Edith; Mulalic, Ismir; Pilegaard, Ninette
}

Publication date:

2013

Document Version

Publisher's PDF, also known as Version of record

Link back to DTU Orbit

Citation (APA):

Madsen, E., Mulalic, I., \& Pilegaard, N. (2013). A model for estimation of the demand for on-street parking.

\section{General rights}

Copyright and moral rights for the publications made accessible in the public portal are retained by the authors and/or other copyright owners and it is a condition of accessing publications that users recognise and abide by the legal requirements associated with these rights.

- Users may download and print one copy of any publication from the public portal for the purpose of private study or research.

- You may not further distribute the material or use it for any profit-making activity or commercial gain

- You may freely distribute the URL identifying the publication in the public portal

If you believe that this document breaches copyright please contact us providing details, and we will remove access to the work immediately and investigate your claim. 


\section{MPRA \\ Munich Personal RePEc Archive}

\section{A model for estimation of the demand for on-street parking}

Edith Madsen and Ismir Mulalic and Ninette Pilegaard

Technical University of Denmark, Technical University of Denmark, Technical University of Denmark

16. December 2013

Online at http://mpra.ub.uni-muenchen.de/52361/

MPRA Paper No. 52361, posted 20. December 2013 21:42 UTC 


\title{
A model for estimation of the demand for on-street parking*
}

\author{
Edith Madsen, Ismir Mulalic and Ninette Pilegaard \\ Technical University of Denmark
}

December 16, 2013

\begin{abstract}
This paper presents a stylized econometric model for the demand for on-street parking with focus on estimation of the elasticity of demand with respect to the full cost of parking. The full cost of parking consists of a parking fee and the cost of searching for a vacant parking space (cruising). The cost of cruising is usually unobserved. Ignoring this issue implies a downward bias of the elasticity of demand with respect to the total cost of parking since the cost of cruising depends on the number of cars parked. We also demonstrate that, even when the cost of cruising is unobserved, the demand elasticity can be identified by extending the econometric model to include the spatial interaction between the parking facilities. We illustrate the model with on-street parking data from Copenhagen and find indications of a somewhat greater parking demand elasticity than is usually reported in the literature.
\end{abstract}

Keywords: on-street parking, demand estimation.

JEL classification: C51, R41, L91.

*Corresponding author. Tel.: +45 4525 6524. E-mail addresses: imu@transport.dtu.dk (I. Mulalic),np@transport.dtu.dk (N. Pilegaard), edma@transport.dtu.dk (E. Madsen). 


\section{Introduction}

Cities around the world use parking policies to regulate the demand for onstreet parking and, to some extent, also the level of urban congestion. It is therefore of relevance to estimate the sensitivity of the demand for on-street parking to cost. The full cost of parking (the generalised cost of parking) consists of a parking fee and in addition the cost of searching for a vacant parking space (cruising). The cost of cruising is typically unobserved, ${ }^{1}$ but ignoring it biases the estimate of the demand elasticity because the cost of searching for a vacant parking space depends on the number of cars parked, i.e. the demand for parking. This paper proposes a solution to this problem. We formulate an econometric model with both parking fees and cruising for parking as arguments for the demand elasticity for parking. We show how this demand elasticity can be identified, even in situations where cruising for parking is unobserved, when the model is extended to include spatial interaction between the parking facilities.

The economic literature has shown a growing interest for regulatory parking policies. Verhoef et al. (1995) analyse different parking policies as a substitute to road pricing and find that the use of parking fees is superior to physical restrictions on parking space supply. Fosgerau \& de Palma (2013) show that workplace parking charging schemes can be used as a substitute for the time-varying toll to reduce urban congestion. Moreover, it is typically argued, that parking should be priced at its opportunity cost, just like any other commodity. Arnott et al. (2005) identify a potential triple dividend from optimal parking pricing: reduced cruising for parking, reduced congestion (travel time savings), and the use of parking revenues to lower other taxes (reduced deadweight loss caused by tax distortions). However, in real life parking facilities are often underpriced (Small \& Verhoef, 2007). This underpricing leads to cruising for parking which is a pure loss from a social welfare perspective (Shoup (2005) and Calthrop \& Proost (2006)). Arnott \& Inci (2006) argue that parking pricing (especially hourly parking fees)

\footnotetext{
${ }^{1}$ One exception is Van Ommeren et al. (2012) that examines cruising for parking. However, in this study information on parking fees is not available.
} 
has also the downside that it can increase congestion by implying shorter parking durations and thus increase traffic congestion by increasing parking turnover. Arnott et al. (2012) examine the optimal level of curbside parking capacity when both urban transport and curbside parking are underpriced and consider the situation where there is garage parking as alternative to the curbside.

Despite the comprehensive treatment of parking pricing, including the dependence of the costs of cruising on the number of cars parked, in the theoretical urban economics literature (see e.g. Anderson \& de Palma (2004)), there is a rather surprising absence of accurate empirical estimates of the effect of the cost of parking on the demand for parking. This effect is important as it is required for a rigorous welfare analysis of a parking policy. Several studies estimate the price elasticity of demand for parking ignoring the cost of cruising (see e.g. Kelly \& Clinch (2009) and Hensher \& King (2001)). Hence, there is a knowledge gap between the theoretical and empirical literature. This paper goes some way toward filling this gap.

Many cities collect citywide parking data which usually includes the occupancy rates (the number of cars parked divided by the number of parking spaces) and the parking fees. ${ }^{2}$ In this paper, we illustrate our model with data provided by the city of Copenhagen, covering on-street parking in the city of Copenhagen, which is a high-density area with strong parking capacity constraints as often present in high-density metropolitan areas and historical city centres. This paper provides a framework to clarify the identification of the effect of the cost of parking consistent with the underlying economic theory. The framework is suitable for the parking data often collected. We discuss also the implications for estimation. We show that if only parking fees are observed, the effect of the cost of parking cannot be identified using a reduced form parking demand equation. In addition the effect of the parking fee is always less than the effect of the cost of parking in absolute value. We also show that the effect of the cost of parking can be identified, even if the

\footnotetext{
${ }^{2}$ See e.g. Institute of Transportation Engineers (2012), Puget Sound Regional Council (2012), Seattle Department of Transportation (2011), Felsburg Holt \& Ullevig (2009) and NYC Department of Transportation (2009).
} 
cost of cruising is unobserved, by extending the econometric model to include the spatial interaction between the parking facilities (streets). If both the costs of searching for parking and the parking fees are observed the effect of the cost of parking can be estimated using instrumental variable techniques.

The next section introduces an econometric model for the demand for on-street parking; Section 3 presents the empirical illustration and Section 4 concludes.

\section{An econometric model of the demand for parking}

In this section we specify an econometric model for the demand for on-street parking. First, in Section 2.1, we describe a very simple model without spatial interactions. Then, in Section 2.2, we consider an extension of the model that takes the spatial interaction into account.

For both models, the demand for on-street parking is described in terms of the occupancy rate, i.e. the number of parked cars relative to the number of legal parking lots. The supply of parking lots is assumed to be constant and thus, the occupancy rate reflects the demand for on-street parking. There is no modelling of external factors affecting the demand for parking by e.g. affecting the overall traffic demand or number of cars. In this way, the model proposes a partial description without interaction with other sectors. We also simplify by ignoring the effect on the demand for on-street parking of other parking alternatives (e.g. private parking houses). We suggest that this effect is small and thus of little importance, see Section 3.1.

\subsection{A simple model}

First, let the demand for parking in street $i$ at period $t$ in terms of the occupancy rate, $O_{i t}$, (the number of cars parked divided by the number of 
parking spaces) be given by

$$
\begin{aligned}
O_{i t} & =\alpha_{i}+\beta c_{i t}+\varepsilon_{i t} \\
c_{i t} & =p_{i t}+S\left(O_{i t}\right)
\end{aligned}
$$

where $c_{i t}$ is the total cost of parking in street $i$ at period $t, \alpha_{i}$ is a streetspecific fixed effect, and $\varepsilon_{i t}$ is an idiosyncratic error term. The cost $c_{i t}$ consists of a direct cost $p_{i t}$ (a parking fee) and an indirect cost, $S\left(O_{i t}\right)$, that reflects the searching costs (cruising) and depends on the occupancy rate $O_{i t}$. In line with the literature we assume that the searching cost function $S(\cdot)$ is increasing in the occupancy rate, see e.g. Anderson \& de Palma (2004). Altogether equations (1)-(2) express that an increase in the parking fee reduces $O_{i t}$ and thus increases the number of vacant parking spaces; this in turn implies a lower cruising time and by that a lower cost of searching. The specification highlights the fact that the cost of searching, and by that the cost $c_{i t}$, is an endogenous variable in the parking demand equation.

In our dataset, we do not have any information on searching in terms of time and costs and therefore we will specify the functional relationship between the searching costs and the occupancy rate in order to arrive at a reduced form equation for $O_{i t}$ (see below). It is important to note that if we did have information on searching then the total cost of parking $c_{i t}$ could be calculated and a valid instrument for $c_{i t}$ would be the parking fee $p_{i t}$. Consequently, the parameter $\beta$ could be estimated by IV estimation.

The street-specific fixed effects capture all time-invariant differences in the demand for parking between streets such as the distance to the location of shopping and leisure activities and the number of residence parking permits (residents pay an annual fee and in return gain the right to park on-street in a specific area). Very importantly, the inclusion of street-specific fixed effects controls for endogeneity of the average parking fee level in a street. It is typically the case that the fees are higher in the city center where the demand is also high and vice versa in the areas further away from the city center. The street-specific fixed effects allow for this type of endogeneity but excludes the case where a change in the parking fee over time is a response 
to a change in demand. We find that this assumption is reasonable in most empirical applications to on-street parking. Typically, these adjustments are a result of some political decisions rather than demand reactions. ${ }^{3}$

In order to obtain a reduced form equation for the parking demand in terms of the occupancy rate $O_{i t}$ we need to specify how the searching costs depend on the occupancy rate. We assume that the costs of searching are linear in the occupancy rate:

$$
S\left(O_{i t}\right)=a+b O_{i t} \quad \text { where } b>0
$$

Using (3) it is straightforward to show that the reduced form equation implied by equations (1)-(2) is

$$
O_{i t}=\tilde{\alpha}_{i}+\tilde{\beta} p_{i t}+\tilde{\varepsilon}_{i t}
$$

where $\tilde{\alpha}_{i}=\left(\alpha_{i}+a \beta\right) /(1-b \beta), \tilde{\beta}=\beta /(1-b \beta)$ and $\tilde{\varepsilon}_{i t}=\varepsilon_{i t} /(1-b \beta)$. For $\beta<0$ then $\tilde{\beta} \in] \beta, 0]$ since $b>0$ such that the parameter corresponding to $p_{i t}$ in the reduced form equation is less than $\beta$ in absolute value. The parameter describes the total effect of increasing the parking fee. The direct effect is that it will decrease the demand for parking and the indirect effect is that this in turn will decrease the searching cost which will increase the demand for parking. The larger the value of $b$ the smaller the absolute value of the total effect. From this reduced form equation it is not possible to identify the parameter $\beta$ in the demand equation and the parameters $a$ and $b$ in the searching cost function separately. However, if the costs of searching are piecewise linear in the occupancy rate then all parameters are identified if there are streets where the occupancy rate is below a threshold value of the occupancy rate where the cost of searching is zero (see Appendix A).

Obviously, the assumption about the searching cost being linear in the occupancy rate is strong and a more realistic assumption would be that the marginal cost of searching is increasing in the occupancy rate. This could for example be modelled as $S(O)=c /(1-O)$ where $c>0$ as done in Anderson $\&$ de Palma (2004). However, this will lead to a more complicated reduced

\footnotetext{
${ }^{3}$ This is reasonably to be the case for our illustrative example from the city of Copenhagen, see Section 3.1.
} 
form equation for the occupancy rate which is not useful in empirical work.

\subsection{Spatial interaction between the parking facilities}

The framework in Section 2.1 assumes that the demand for parking in a specific street is independent of the cost of parking in all other streets. This assumption is obviously not likely to hold in practice since the demand for parking in a specific street expectedly will also depend on the cost of parking in neighboring streets. We now extend the model to allow for this. More formally, we assume that the demand for parking in street $i$ depends on both the cost of parking in street $i$ and on the cost of parking in neighboring streets $j \neq i$. As before, the cost of parking consists of a parking fee and a searching cost which is increasing in the occupancy rate. The demand for parking in street $i$ at time $t$ is now given by:

$$
\begin{aligned}
O_{i t} & =\alpha_{i}+\beta c_{i t}+\gamma \sum_{j \neq i} w_{i j} c_{j t}+\varepsilon_{i t} \\
c_{j t} & =p_{j t}+S\left(O_{j t}\right)
\end{aligned}
$$

The parameter $\gamma$ corresponding to the term $\sum_{j \neq i} w_{i j} c_{j t}$ in equation (5) describes how the demand for parking in a specific street is affected by the costs of parking in neighboring streets. The spatial weights $w_{i j}$ for $j \neq i$ are prespecified and each weight defines the exact neighboring effect of a specific street. We use the following geographically derived weights:

$$
w_{i j}=\exp \left(-\theta d_{i j}\right)
$$

where $d_{i j}$ is the the shortest route distance between streets $i$ and $j$, and $\theta>0$ is a specified constant (not a parameter that can be estimated). The weights are exponentially decreasing in the distance and approaches zero as the distance increases. We use the minimax normalization of the weights (a common scaling of all weights) and note that this normalization preserves the symmetry such that $w_{i j}=w_{j i}$. For a more extensive discussion of spatial weights, see e.g. Anselin (1988) and Upton \& Fingleton (1985).

The model defined by equations (5)-(6) allows for substitution between 
the demand for parking in different streets as given by the spatial weights and the model parameters. The model implies the following own and cross elasticities with respect to the total parking cost:

$$
\begin{aligned}
e_{i i} & \equiv \frac{\partial O_{i t}}{\partial c_{i t}} / \frac{O_{i t}}{c_{i t}}=\beta \frac{c_{i t}}{O_{i t}} \\
e_{i j} & \equiv \frac{\partial O_{i t}}{\partial c_{j t}} / \frac{O_{i t}}{c_{j t}}=\gamma w_{i j} \frac{c_{j t}}{O_{i t}}
\end{aligned}
$$

Intuitively, we would expect $\gamma>0$ such that all other streets are substitutes for parking in one particular street. Everything else equal, the closer two streets are located to each other the higher the substitution effect is, i.e $e_{i j}>e_{i k}$ for $d_{i j}<d_{i k}$ since $w_{i j}>w_{i k}$. It is important to note that the difference in substitution effect between two different streets is determined by the parameter $\theta$ which is prespecified and not estimated. In this study, the parameter $\theta$ is set at 10 . This implies that spatial weights are close to zero $(<0.1)$ for streets more than 0.5 kilometres away. The need to specify the spatial structure a priori is obviously a limitation in all spatial models, see Gibbons \& Overman (2012) for a discussion of this.

As our dataset does not contain information on searching time or searching cost, equations (5)-(6) cannot by used directly in estimation. Instead our approach is to impose assumptions on the relationship between the searching cost and the occupancy rate and use that to reach a reduced form equation that can be estimated. As equation (3) in Section 2.1 we assume that the costs of searching are linear in the occupancy rate, i.e. $S(O)=a+b O$. Using this, equations (5)-(6) can be written as (in matrix notation):

$$
O_{n t}=\tilde{\alpha}_{n}+\tilde{\beta} p_{n t}+\tilde{\gamma} W_{n} p_{n t}+\lambda W_{n} O_{n t}+\tilde{\varepsilon}_{n t}
$$

where the $n$-vector $\tilde{\alpha}_{n}$ have elements $\left(\alpha_{i}+a \beta+a \gamma \sum_{j \neq i} w_{i j}\right) /(1-b \beta)$, parameters are defined as $\tilde{\beta}=\beta /(1-b \beta), \tilde{\gamma}=\gamma /(1-b \beta)$ and $\lambda=b \tilde{\gamma}$, the weight matrix $W_{n}$ has elements $w_{i j}$ and zeros in the diagonal, and the error term $\tilde{\varepsilon}_{n t}$ is iid $N\left(0, \tilde{\sigma}^{2} I_{n}\right)$ with $\tilde{\sigma}^{2}=\sigma^{2} /(1-b \beta)^{2}$ across $t=1, \ldots, T$. This is the standard Spatial Durbin Model (SDM) with fixed effects $\tilde{\alpha}_{n}$, exogenous regressors $p_{n t}$ and $W_{n} p_{n t}$ and the spatially lagged endogenous regressor 
$W_{n} O_{n t}$, see e.g. LeSage \& Pace (2009). Like in the simple framework of Section 2.1 the parameters of main interest, $\beta$ and $\gamma$ in equation (5), do not appear as parameters in the SDM model and as before we have that when $\beta<0, \gamma>0$ and $b>0$ then $\tilde{\beta} \in] \beta, 0]$ and $\tilde{\gamma} \in[0, \gamma[$. Therefore estimates of $\tilde{\beta}$ and $\tilde{\gamma}$ will underestimate the marginal effects of increasing parking costs $\beta$ and $\gamma$. However, the parameters $\beta, \gamma$ and $b$ can be obtained as functions of the parameters $\tilde{\beta}, \tilde{\gamma}$ and $\lambda$ and hence the parameters $\beta$ and $\gamma$ in the demand for parking equation (5) can be estimated. See Appendix B for details.

Estimation of equation (10) is performed by maximum likelihood as described in Lee (2004). In addition, Lee $(2004,2007)$ investigates the sources of identification and various reasons of failure to identify the model parameters in different versions of spatial autoregressive (SAR) models. It is shown that in case the exogenous regressors (in our case $p_{n t}$ and $W_{n} p_{n t}$ ) and the spatially lagged regressor are colinear the source of identification will be coming from the covariance structure of the error terms. This in turn implies that the covariance structure of the error term in equation (10) must be correctly specified. In our case we assume that the elements in the error term are independent across $i, t$ with constant variance. Obviously, identification that relies on variation in exogenous variables is more appealing since assumptions imposed on the error term such as constant variance are somewhat arbitrary. The problem is discussed in a recent paper by Gibbons \& Overman (2012) and is similar to the identification problem in models where the outcome variable depends on some expected value of the outcome variable, the reflection problem, see Manski (1993).

Finally, Lee \& Yu (2010) show that estimation of a spatial model with unit-specific fixed effects is straight forward. It is done by using results from standard panel data models, i.e. maximization of the conditional likelihood function gives consistent estimators of the model parameters where the conditioning is done with respect to unit-specific averages of the dependent variable as sufficient statistics for the unit-specific effects. 


\section{Empirical illustration}

This section of the paper presents an illustration of the application of the econometric model. We use parking data from the city of Copenhagen. With this it is in principle possible to test the model and estimate demand elasticity of parking with respect to the full cost.

Section 3.1 describes the parking market in the city of Copenhagen. It also includes a discussion of a number of key assumptions that underlie the identification of the model and the interpretation of its parameters. The data set provided by the city of Copenhagen for the analysis is described in Section 3.2 and estimation results are discussed in Section 3.3. We discuss our findings on the parking price elasticity, relate our result to the estimates provided by the existing literature and conclude the section by discussing the results obtained from estimation of a standard spatial model with streetspecific fixed effects.

\subsection{Parking in the city of Copenhagen}

About two-third of the parking spaces in the city of Copenhagen are onstreet an hence this is the dominating way of parking (Københavns Kommune (2012)). The city of Copenhagen has, as many other larger cities, a long history of paid parking (both for publicly provided as well as privately provided parking places). In 1990 the city of Copenhagen initiated a new system for payments for parking, where the central city was divided into different zones. The principles of this system is still used today. The purpose with the system was to reduce the traffic and the number of parked cars in the city, especially commuting in cars to workplaces in central Copenhagen (Københavns Kommune, 2009). In the zonal system all on-street parking is charged a fee depending on the duration of the parking, time of the day and the location of the zone. The zones closest to the historical city center are more expensive. Many other European cities use similar systems where payment for on-street parking varies across zones and time-intervals.

In the introductory year (2006) the hourly parking fee level was determined by the level of the observed occupancy rates (demand). The intention 
was to reduce cruising for parking. In the following years the city authorities increased the parking fees by 1 DKK a year (in nominal terms) without taking into account the development in the occupancy rates and hence not as a reaction on the demand. ${ }^{4}$

At present the zonal system covers three zones: red is the city center with few residents and many shops, restaurants and offices, green and blue have more residents. These zones has been in use since 2007 .

\subsection{The data}

The data used in the empirical analysis is provided by the city of Copenhagen. The data is census data and covers the years 2008-2011 with semi-annual census (in April and September, starting with September 2008). In total we have 6 census and for each census there are three daily counts (at 12:00, 17:00 and 22:00). The census covers the central Copenhagen (the four parking zones). For all streets in this area we know the number of legal parking spaces as well as the number of occupied spaces, for each of the three daily counts. We do not have information about cruising costs or cruising time. Furthermore, we do not have information about alternative parking (e.g. private parking houses and workplace parking).

Table 1 shows the number of parking lots, the number of parked cars, and the mean occupacy rates for the four parking zones (772 streets) recorded in April 2011. The number of parking spaces and the distribution among the zones are almost the same in the three years that we consider.

The parking fees for the zones are shown in Table 2. The parking fee for the red zone (the city center) is almost three times as high as for the blue zone. Outside the three zones (the outer) there are generally no fees for parking. We also see that the real prices have been almost constant for the years 2008-2011. This obviously represents a limitation for the econometric analysis.

\footnotetext{
${ }^{4}$ Special rules apply for residents in a parking zone such that residents are able to park close to their homes on very favorable conditions. The price of a resident parking permit is about $€ 90$ per year per car. The parking permit is connected to a specific car and there is no limit to the number of residence parking permits available.
} 
Table 1: Parking on-street, April 2011

\begin{tabular}{lccl}
\hline \hline Zone & Parking spaces & Number of parked cars & Mean occupancy rate \\
\hline Red & 980 & 1,025 & $106.55 \%$ \\
& & & $(20.83)$ \\
Green & 6,589 & 5,061 & $80.12 \%$ \\
& & & $(23.22)$ \\
Blue & \multirow{2}{*}{17,565} & \multirow{2}{*}{11,537} & $69.27 \%$ \\
& & & $(25.29)$ \\
Outer & 13,520 & \multirow{2}{*}{10,053} & $76.37 \%$ \\
& & & $(28.59)$ \\
\hline Total & 38,650 & 27,675 & $75.63 \%$ \\
& & & $(27.40)$ \\
\hline
\end{tabular}

Notes: std. dev. are in paranthesis; censoring $\mathrm{O}=130 \%$, 772 streets.

In the empirical analysis we have reduced the dataset in two ways. First, the three different time counts represent different traffic situations. For example, in the Danish National Travel Survey we see many shoppers and short term parkers at noon while residents are more dominating after work hours. For the following empirical analysis we choose to use the figures from the noon count $(12: 00 \mathrm{am})$. Second, the dataset provides the number of occupied spaces as well as the number of legal parking spaces for each street. With this information we can calculate the occupancy-rate for each street. Note that the occupancy rate can be above $100 \%$. This is possible since the number of legal parking lots is rarely physically marked and thus it is possible to deviate from the estimated number depending on the size of the cars and the density of the standard size of parked cars. Because of this we accept an occupancy rate above $100 \%$ in our dataset but choose to censor the occupancy rates above $130 \% .^{5}$

Figure 1 shows that the mean occupancy rate for red zone (central Copenhagen) is above $100 \%$ which indicates that there is generally no excess supply

\footnotetext{
${ }^{5}$ This rule of censoring occupancy rates above $130 \%$ is based on the technical analysis of the parking capacity in the City of Copenhagen (see also http://www.kk.dk/Borger/ByOgTrafik/Parkeringsstrategi/infomateriale/ parkeringstaelinger_2.aspx (accessed 01/11/2012)).
} 
Table 2: Parking fees (DKK/hour)

\begin{tabular}{ll|rrrr|rrrr}
\hline \hline Zone & Time & 2008 & 2009 & 2010 & 2011 & 2008 & 2009 & 2010 & 2011 \\
\hline & & \multicolumn{3}{|c|}{ real terms } & \multicolumn{4}{c}{ nominal terms } \\
\hline \multirow{2}{*}{ Red } & day & 25.15 & 26.73 & 27.06 & 26.57 & 26 & 28 & 29 & 29 \\
& night & 2.90 & 2.86 & 2.80 & 2.75 & 3 & 3 & 3 & 3 \\
Green & day & 15.47 & 16.23 & 15.86 & 15.57 & 16 & 17 & 17 & 17 \\
& night & 2.90 & 2.86 & 2.80 & 2.75 & 3 & 3 & 3 & 3 \\
Blue & day & 8.70 & 9.55 & 9.33 & 9.16 & 9 & 10 & 10 & 10 \\
& night & 2.90 & 2.86 & 2.80 & 2.75 & 3 & 3 & 3 & 3 \\
\hline \hline
\end{tabular}

Notes: 1 DKK $=0.13 €$.

of parking places in the zone, i.e. empty spots will generally be filled immediately and thus cruising for parking is present. For the green and blue zones as well as for the outer zone we also find very high occupancy rates at all times of the day indicating little or no excess supply and potentially cruising for parking. We also note that the occupancy rates are highest in the red zone at the $12.00 \mathrm{am}$ (noon) count implying that crusing for parking is present in the data we use in our analysis.

\subsection{Empirical results}

We now describe the empirical results. We first present our findings on the parking price elasticity. Next, we discuss the results obtained from estimation of a standard spatial model with street-specific fixed effects.

First, we estimate the simple model with the reduced form equation for the demand for on-street parking based on (4) in terms of the occupancy rate with the parking fee as explanatory variable as well as street-specific fixed effect. Since the supply of on-street parking has been constant in the period of the observation, we interpret the effect of the parking fee on the occupancy rate as a demand effect.

As mentioned before, we consider the noon-count. There are more reasons for this choice. It is important to consider a situation with many shoppers among the car-riders as these are most relevant for the analyses of parking 


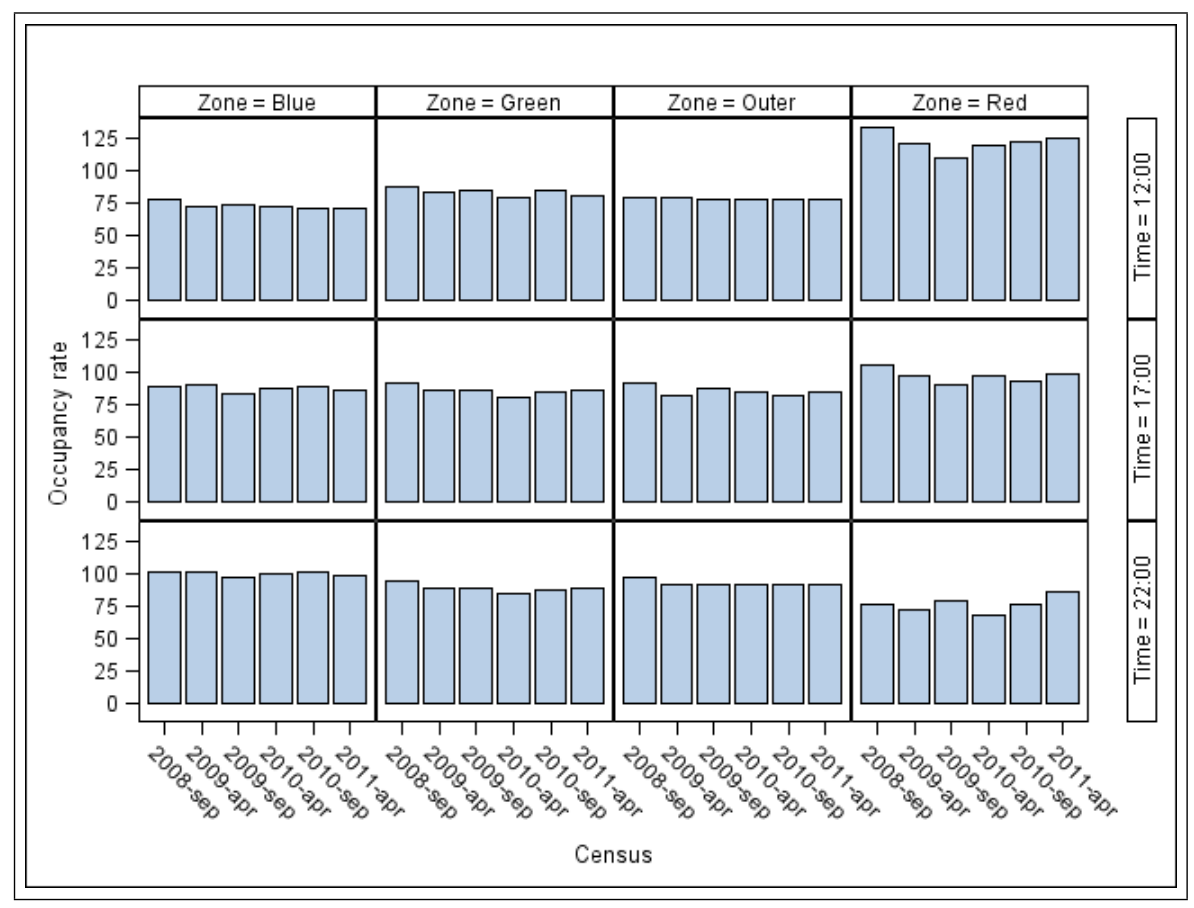

Figure 1: Occupancy rate (mean)

cost sensitivity and the shoppers are more dominating among the parkers at noon.

Table 3 shows the estimation results. As we expected, an increase in the parking fee decreases demand for on-street parking. The parameter associated with the parking fee $(\widetilde{\beta})$ is estimated to -2.807 . The parameter estimate is tight and indicates a plausible effect. The $95 \%$ confidence interval is estimated to be from -4.383 to -1.234 . Moreover, an F-test on the joint significance of the included street-specific fixed effect indicates that the effects are significant $(F(771,3859)=14.94)$. It means that demand for on-street parking varies across streets in the city of Copenhagen, i.e. the demand for on-street parking in a specific street is affected by the time-invariant factors such as e.g. street attributes (e.g. one-way traffic), number of residential units, the distance to the location of shopping and leisure activities, the number of residence parking permits, supply of public transport, etc.

The estimation result allows us to derive the parking fee elasticity. ${ }^{6}$ Notice

\footnotetext{
${ }^{6}$ The parking fee elasticity is defined as $\varepsilon_{O, p}=\frac{\partial O}{\partial p} \frac{p}{O}=\widetilde{\beta} \frac{p}{O}$.
} 
Table 3: Simple model for on-street parking in terms of the occupancy rate

\begin{tabular}{ll}
\hline \hline & {$[1]$} \\
\hline Parking fee (DKK/hour) & $-2.807^{* * *}$ \\
& $(0.804)$ \\
Constant & $100.542^{* * *}$ \\
& $(6.764)$ \\
Street-specific fixed effect & yes \\
\hline R-sq & 0.037 \\
Number of obs. & 4,632 \\
\hline
\end{tabular}

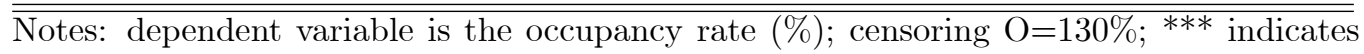
that estimates are significantly different from zero at the 0.01 level; standard errors are in parentheses.

here that the parking fee elasticity is different from the elasticity of demand with respect to total cost of parking, since the total cost of parking consists of a parking fee and the cost of cruising. The parking fee elasticity in the red zone (the historical city center) at the sample average of the occupancy rate in the red zone (106.55\%) and the parking fee of 26 DKK/hour (see Table 2) is -0.69 , i.e. raising the parking fee in the red zone by $1 \%$ reduces demand for on-street parking in the historical city center by $0.69 \%$. The parking fee elasticity for the blue zone at the sample averages of the occupancy rate in the blue zone (69.27\%) and the parking fee of $10 \mathrm{DKK} /$ hour is -0.41 . However, these are underestimates of the parking demand elasticity because, as shown in section 2.1, the parameter corresponding to the parking fee in the reduced form equation $(\widetilde{\beta})$ is less than the parameter corresponding to the total cost of parking $(\beta)$ in absolute value.

Our estimate of the parking fee elasticity is however consistent with those reported in a number of papers indicating the potential impact of crusing bias on the parking price elasticities offered by the litterature. The cruising bias is caused by the fact that while the cost of cruising is usually unobserved, ignoring it bias the estimation of the price elasticity of demand because of the dependence of the costs of cruising on the number of cars parked, i.e. the demand for on-street parking. In the review paper, Marsden (2006) proposes 
a range from -0.6 to -0.1 for the parking demand elasticities (defined in his study as the percent change in demand of the percent change of parking costs or parking fees), with -0.3 being the most frequently cited value (see also TCRP (2005)). Kelly and Clinch (2009) report the average price elasticity of parking demand (where parking cost is defined as a parking fee per hour) of -0.29 . Moreover, the interpretation of the parking fee elasticity strongly depends on the assumption with respect to the level of residential parking, because the estimate of the parking fee elasticity depends on the ratio of the average parking fee and the average occupancy rate. This occupancy rate is highly affected by the amount of residential parking as a large number of parking spaces can be more or less permanently occupied by users with resident parking permits. Unfortunately, the information on the share of cars parked using the residential parking permit in the city of Copenhagen is not available. Based on some Danish experienced practitioners' best guesses (different analyses conducted by the Municipality of Copenhagen and the bordering municipality Frederiksberg) this share is expected to be in the range of $10-30 \%$. The parking fee elasticity is then closer to -1 . This is also in line with the usual findings. Hensher and King (2001) propose parking price elasticity (the percent change in the probability of choosing to park in a given area of a one percent increase in the hourly parking fee) in the range from -1.02 to -0.48 . Our findings indicate, that due to the cruising bias, the parking demand elasticity (the car drivers' response to an increase in the total cost of parking) is most likely larger than proposed in the literature.

Estimation of the reduced form spatial model in equation (10) is in principle straight forward, see Section 2.2. However, in practice it turns out to be difficult because in our data set the parking fees at a given point in time are the same within a specific parking zone. This means that for streets where the distance to streets in other zones is large the variables $p_{i t}$ and $\sum_{j \neq i} \omega_{i j} p_{j t}$ are proportional. In our analysis where we have chosen $\theta=10$ this is the case for streets where the distance to other zones is greater than $0.5 \mathrm{~km}$. This holds for streets within the center of a zone and for streets on the boundary of a zone with no border to other zones. It implies that the variables $p_{n t}$ and $W_{n} p_{n t}$ are close to being colinear and consequently it is not 
Table 4: Spatial Durbin model for on-street parking in terms of the occupancy rate

\begin{tabular}{lrr}
\hline \hline & Estimates & Std. errors \\
\hline$\lambda$ & 0.273 & 0.121 \\
$\tilde{\beta}$ & -1.910 & 1.544 \\
$\tilde{\gamma}$ & -4.287 & 7.564 \\
$\tilde{\sigma}^{2}$ & 231.1 & 5.262 \\
Street-specific fixed effect & \multicolumn{2}{c}{ yes } \\
\hline$\theta$ & \multicolumn{2}{c}{10} \\
Number of obs. & \multicolumn{2}{c}{4,632} \\
\hline \hline Notes: dependent variable is the occupancy rate (\%), censoring $\mathrm{O}=130 \%, 772$ streets.
\end{tabular}

possible to estimate the corresponding parameters $\tilde{\beta}$ and $\tilde{\gamma}$ precisely. Table 4 shows the results from the estimation. We see that the point estimate of $\tilde{\beta}$ has the correct sign but the precision is poor. Moreover, the point estimate of $\tilde{\gamma}$ has the wrong sign and again precision is poor. The cause of this finding is the colinearity between $p_{n t}$ and $W_{n} p_{n t}$. As shown in Appendix B estimates of the parameters of interest $b, \beta$ and $\gamma$ can be recovered from the parameter estimates in Table 4. However, given the wrong sign of $\tilde{\gamma}$ and the poor precision of estimates of $\tilde{\beta}$ and $\tilde{\gamma}$ this is not feasible. Altogether, given the problems with the estimation of the spatial model caused by the limited variation in the exogenous variables we find that the results of our empirical analysis of the spatial model are not very informative. Obviously it would be of interest to perform the analysis using a data set with the appropiate amount of variation across time and across units in future work.

\section{Conclusion}

This paper deals with estimation of the elasticity of the demand with respect to the full cost of parking for on-street parking. We take into account the data availability, i.e. (city) transport authorities collect parking data that includes the occupancy rates and sporadically and if relevant the parking fees. This paper proposes a new methodological framework to clarify the 
identification of the effect of the cost of parking (consisiting of the costs of searching for parking (cruising) and a parking fee) on the demand when the cost of searching is unobserved.

We illustrate the model using on-street data from the city of Copenhagen for the years 2008-2011. Limitations in the data prevents us from estimating the elasticity properly but our illustrations suggest that the parking demand elasticity is most likely larger than the one proposed in the literature.

Our findings have a number of implications. First it demonstrates that parking fees can potentially be a useful policy instrument to organize the parking market and to reduce the external costs of traffic such as congestion (cruising), air pollution, and other relevant local environmental externalities. It also demonstrates that, in line with the literature (see Arnott et al., 1991), a spatially differentiated parking fee is necessary to induce the optimal parking pattern. Second, the proposed empirical methodology can be useful for the estimation of other similar reduced form demand equation describing the demand with the constrained capacity. In particular the reduced form demand equation resulting from a bottleneck model is a good example (see e.g. Arnott et al. (1993)). Finally, the proposed methodology makes it possible to make a straightforward extension of the demand model to include spatial interactions. In this way many of the identification problems in applied spatial economics can be avoided.

Acknowledgement 1 The authors thank Mogens Fosgerau, Jos Van Ommeren and Eren Inci for their useful suggestions on an earlier draft and research assistant Sara Tvile Marker Sørensen for data management. We are grateful to the city of Copenhagen (Ase Boss Henrichsen and Anders Møller) for providing the data. Seminar participants at the Kuhmo Nectar Conference on Transportation Economics 2012, LATSIS 2012, and DTU Transport at the Technical University of Denmark also provided helpful comments. Research support from the Danish Council for Strategic Research is acknowledged. All remaining errors are the authors' alone. 


\section{Appendices}

\subsection{Appendix A}

Assume now that the costs of searching are piecewise linear in the occupancy rate

$$
S\left(O_{i t}\right)=\begin{array}{cl}
0 & \text { if } O_{i t}<\Theta \\
a+b O_{i t} & \text { if } O_{i t} \geq \Theta
\end{array}
$$

It means that the cost of searching is zero when the occupancy rate is less than a threshold value $\Theta$ (e.g. $\Theta=70 \%$ ) and linear and increasing for values above $\Theta$. This might be a more realistic assumption than having the costs being linear in the occupancy rate since if the occupancy rate is low then there will be empty parking spaces and the cost of searching is zero. The threshold value at $\Theta$ reflects that if the occupancy rate is above this level then it is more likely that all spaces are occupied which implies cruising. Note also that, as emphasised by Arnott \& Inci (2006), given perfect information about parking spaces and optimal pricing of parking, cruising time is (close to) zero.

The reduced form for the eq.(A.1) is now given by

$$
O_{i}=\begin{array}{cl}
\alpha_{i}+\beta p_{i} & \text { if } p_{i} \geq\left(\Theta-\alpha_{i}\right) / \beta \\
\frac{\alpha_{i}+a \beta}{1-b \beta}+\frac{\beta}{1-b \beta} p_{i} & \text { if } p_{i}<\left(\Theta-\alpha_{i}\right) / \beta
\end{array}
$$

In this case all parameters are identified if there are streets where the occupancy rate is less than $\Theta$. This identification strategy utilises the fact that the expression is non-linear in the exogenous variable. The difficulty is related to the correct censoring of the occupancy rate. The threshold value $\Theta$ should be selected at the level at which the cost of searching turns to zero.

\section{$5.2 \quad$ Appendix B}

This appendix shows how to obtain the parameters $b, \beta$ and $\gamma$ from the parameters $\tilde{\beta}, \tilde{\gamma}$ and $\lambda$ that result from estimation of the spatial model in 
equation (10). The following holds:

$$
\begin{aligned}
b & =\frac{\lambda}{\tilde{\gamma}} \\
\beta & =\frac{\tilde{\beta}}{1+\lambda /(\tilde{\beta} \tilde{\gamma})} \\
\gamma & =\tilde{\gamma}-\frac{\lambda \tilde{\beta}}{1+\lambda /(\tilde{\beta} \tilde{\gamma})}
\end{aligned}
$$

\section{References}

Anderson, S.P. and A. de Palma. 2004. The economics of pricing parking. Journal of Urban Economics 55, 1-20.

Anselin, L. 1988. Spatial Econometrics: Methods and Models. Kluwer Academic, Dordrecht.

Arnott, R., A. de Palma and R. Lindsey. 1993. A Structural Model of PeakPeriod Congestion: A Traffic Bottleneck with Elastic Demand. The American Economic Review, vol.83(1), pp. 161-179.

Arnott, R., T. Rave and R. Schöb. 2005. Alleviating Urban Traffic Congestion. Cambridge, MA, MIT Press.

Arnott, R. and E. Inci. 2006. An integrated model of downtown parking and traffic congestion. Journal of Urban Economics 60, 418-442.

Arnott, R., E. Inci and J. Rowse. 2012. Downtown Curbside Parking Capacity, CESifo Working Paper No. 4085.

Arnott, R., A. de Palma and R. Lindsey. 1991. A temporal and spatial equilibrium analysis of commuter parking. Journal of Public Economics 45, 301-335.

Calthrop, E. and S. Proost. 2006. Regulating on-street parking. Regional Science and Urban Economics, 36, 29-48. 
Felsburg Holt \& Ullevig. 2009. Tennyson street study area parking analysis. Prepared for City and County of Denver. http://www.denvergov.org/Portals/706/documents/Tennsyson\%2038th45th\%20Parking\%20Analysis\%20Oct\%2009.pdf (accessed 18/11/2012).

Fosgerau, M. and A. de Palma. 2013. The dynamics of urban traffic congestion and the price of parking. Journal of Public Economics, forthcoming.

Gibbons, S. and H. Overman. 2012. Mostly pointless spatial econometrics. Journal of Regional Science, vol. 51(2), pp. 172-191.

Glazer, A. and E. Niskanen. 1992. Parking fees and congestion. Regional Science and Urban Economics, 22, 123-132.

Hensher, D.A. and J. King. 2001. Parking demand and responsiveness to supply, pricing and location in the Sydney central business district. Transportation Research A 35 (3), pp. 177-196.

Institute of Transportation Engineers. 2012. Parking Occupancy - Independent Variables. http://www.ite.org/parkinggeneration/variables.asp (accessed 18/11/2012).

Kelly, J. and J.P. Clinch. 2009. Temporal variance of revealed preference on-street parking price elasticity. Transport Policy 16, pp. 193-199.

Københavns Kommune, 2012. Københavns kommunes parkeringsinformation. www.kk.dk/borger/byogtrafik/parkering (accessed 18/11/2012).

Københavns Kommune, 2009. Adfærdsregulering af trafikken og parkeringen. Notat 10-03-2009, Teknik- og miljøforvaltningen.

Lee, L. 2004. Asymptotic distribution of quasi-maximum likelihood estimators for spatial autoregressive models. Econometrica 72(6), 1899-1925.

Lee, L. 2007. Identification and estimation of econometric models with group interactions, contextual factors and fixed effects. Journal of Econometrics $140,333-374$. 
Lee, L. and J. Yu. 2010. Estimation of spatial autoregressive panel data models wih fixed effects, Journal of Econometrics 154, 165-185.

LeSage, J. and R. K. Pace. 2009. Introduction to Spatial Econometrics. Chapman and Hall.

Manski, C. F. 1993. Identification of endogenous social effects: The reflection problem. Review of Economic Studies 60, 531-542.

Marsden, G. 2006. The evidence base for parking policies - a review. Transport Policy 13, pp. 447-457.

NYC Department of Transportation. 2009. PARK Smart Greenwich Village Pilot Program - Results. http://www.nyc.gov/html/dot/downloads/pdf/parksmart_gv_results _july09.pdf (accessed 18/11/2012).

Puget Sound Regional Council. 2012. Parking Inventory. http://www.psrc.org/data/transportation/parking-inventory/ (accessed 18/11/2012).

Seattle Department of Transportation. 2011. Citywide paid parking study and 2011 rates. Technical report. http://www.seattle.gov/transportation/parking/docs/ ParkingStudyTechRep-final.pdf (accessed 18/11/2012).

Shoup, D.C. 2005. The high cost of free-parking. Planners Press, Chicago.

Small, K.A. and E. T. Verhoef. 2007. The economics of urban transportation. Routledge.

TCRP, 2005. Parking Prices and Fees: Traveler Response to Transportation System Changes. Transit Cooperative Research Program Report 95. Transportation Research Board, Washington DC.

Upton, G. J. and B. Fingleton. 1985. Spatial Data Analysis by Example. Volume 1: Point Pattern and Quantitative Data. Wiley, New York. 
Van Ommeren, J.N., D. Wentink and P. Rietveld. 2012. Evidence on cruising for parking. Transportation Research Part A, vol. 46, 1, pp 123-130.

Verhoef, E, P. Nijkamp and P. Rietveld. 1995. The economics of regulatory parking policies: the (im)possibilities of parking policies in traffic regulation. Transportation Research Part A, vol. 29A, 2, pp 141-156. 